M. Battistin, S. Berry, A. Bitadze, P. Bonneau, J. Botelho-Direito, G. Boyd, F. Corbaz, O. Crespo-Lopez, E. Da Riva, C. Degeorge, C. Deterre, B. DiGirolamo, M. Doubek, G. Favre, J. Godlewski, G. Hallewell, S. Katunin, D. Lefils, D. Lombard, S. McMahon, K. Nagai, D. Robinson, C. Rossi ${ }^{\star}$, A. Rozanov, V. Vacek and L. Zwalinski

\title{
The Thermosiphon Cooling System of the ATLAS Experiment at the CERN Large Hadron Collider
}

\section{DOI 10.1515/ijcre-2015-0022}

\begin{abstract}
The silicon tracker of the ATLAS experiment at CERN Large Hadron Collider will operate around $-15^{\circ} \mathrm{C}$ to minimize the effects of radiation damage. The present cooling system is based on a conventional evaporative circuit, removing around $60 \mathrm{~kW}$ of heat dissipated by the silicon sensors and their local electronics. The compressors in the present circuit have proved less reliable than originally hoped, and will be replaced with a thermosiphon. The working principle of the thermosiphon uses gravity to circulate the coolant without any mechanical components (compressors or pumps) in the primary coolant circuit. The fluorocarbon coolant will be condensed at a temperature and
\end{abstract}

*Corresponding author: C. Rossi, Academy of Sciences of the Czech Republic Na Slovance 2, 18221 Praha 8, Czech Republic (Representing the ATLAS Inner Detector Thermosiphon Group), E-mail: cecilia.rossi@cern.ch

M. Battistin, S. Berry, P. Bonneau, J. Botelho-Direito, F. Corbaz,

O. Crespo-Lopez, E. Da Riva, B. DiGirolamo, G. Favre, J. Godlewski, D. Lefils, D. Lombard, L. Zwalinski, CERN, 1211 Geneva 23, Switzerland

M. Doubek, V. Vacek, Czech Technical University, Technická 4, 166 07, Czech Republic

G. Hallewell, A. Rozanov, Centre de Physique des Particules de Marseille, 163 Avenue de Luminy, 13288 Marseille, France

A. Bitadze, SUPA School of Physics and Astronomy, University of Glasgow, G627QB UK

G. Boyd, Department of Physics and Astronomy, University of Oklahoma, Norman, OK73019, USA

C. Degeorge, Indiana University, Department of Physics, Bloomington, IN 47405-7015, USA

C. Deterre, Deutsches Elektronen-Synchrotron, Notkestraße 85, D-22607 Hamburg, Germany

S. Katunin, B.P. Konstantinov Petersburg Nuclear Physics Institute (PNPI), 188300, Russia

S. McMahon, STFC Rutherford Appleton Laboratory - Harwell Oxford, Didcot OX11 OQX, UK

K. Nagai, Department of Physics, University of Innsbruck, Innrain 52, 6020 Innsbruck, Austria

D. Robinson, Department of Physics and Astronomy, University of Cambridge, Cambridge, UK pressure lower than those in the on-detector evaporators, but at a higher altitude, taking advantage of the $92 \mathrm{~m}$ height difference between the underground experiment and the services located on the surface. An extensive campaign of tests, detailed in this paper, was performed using two smallscale thermosiphon systems. These tests confirmed the design specifications of the full-scale plant and demonstrated operation over the temperature range required for ATLAS. During the testing phase the system has demonstrated unattended long-term stable running over a period of several weeks. The commissioning of the full scale thermosiphon is ongoing, with full operation planned for late 2015.

Keywords: multiphase plant, thermosiphon, gravity circulation, fluorocarbon evaporative cooling

\section{Introduction}

The CERN Large Hadron Collider (LHC) is the largest and most powerful particle accelerator in the world. This accelerator was built to study the fundamental constituents of matter and advance our understanding of the structure of the Universe. The ATLAS experiment (Aad et al. 2008) is one of seven major experiments at LHC. It has been built to investigate a wide range of physics reactions produced in high-energy proton-proton collisions. The ATLAS detector (Figure 1) consists of four major elements mounted concentrically around on of the LHC proton beam interaction points: the Inner Detector (ID), calorimeter, muon spectrometer and magnet system. The three detectors are complementary: the ID measures the momentum of each charged particle, while the calorimeter measures the energy of the particles and the muon system makes additional measurements on highly penetrating muons. The magnet system is used to bend the charged particle trajectories to allow momentum measurements. The ATLAS ID coverage ranges between a few centimetres from 


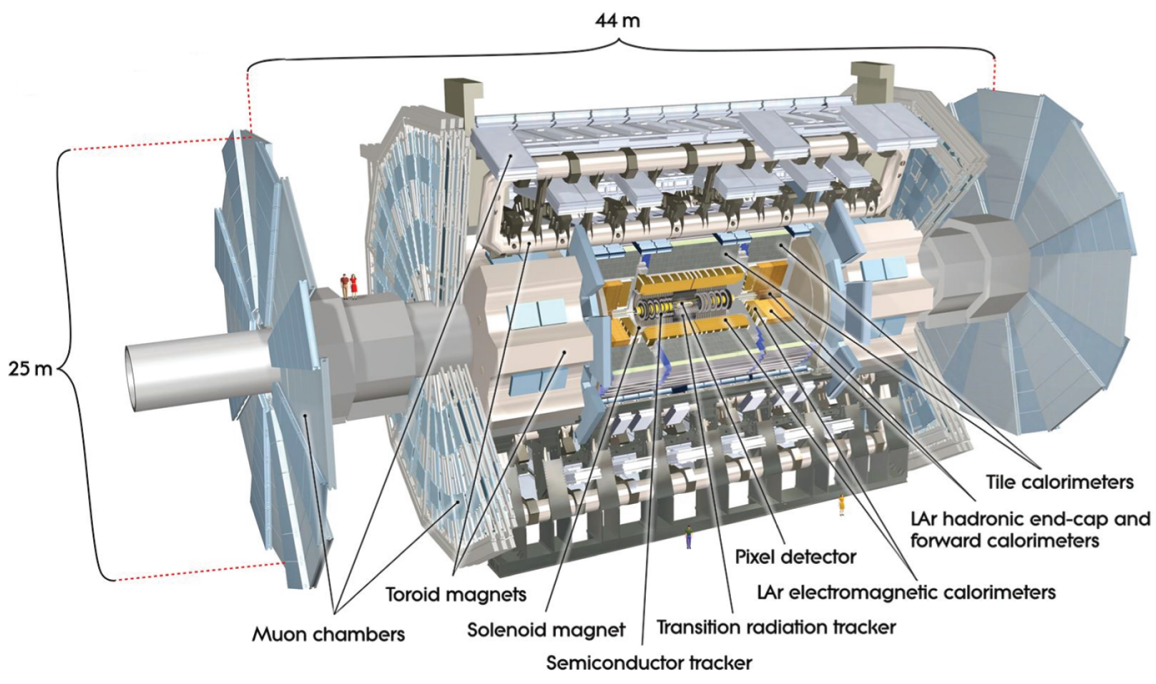

Figure 1: The ATLAS experiment (copyright ATLAS Experiment () 2014 (ERN). the beam axis to 1 meter in radius and 6 metres along the beam axis. Its main function is to measure the paths of charged particles by detecting their passage at discrete points. It combines high-resolution silicon detectors the silicon Pixel detector and SemiConductor Tracker (SCT) - with gas-based tracking elements - the Transition Radiation Tracker (TRT) - at larger radius; all surrounded by a central solenoid (Figure 1). The Pixel and SCT detectors are cooled by a common fluorocarbon evaporative cooling system which is the subject of this paper.

\subsection{The presently-configured ATLAS ID fluorocarbon evaporative cooling system}

An evaporative fluorocarbon cooling system (Aitree et al. 2008) is presently used to cool the ATLAS Pixel and SCT detectors. The substrates of the SCT silicon micro strip modules must presently be maintained at $-7^{\circ} \mathrm{C}$ or lower (ATLAS Collaboration 1997) while those of the pixel detector modules should be at $0^{\circ} \mathrm{C}$ or lower (ATLAS Collaboration 1998), being typically operated around $-10^{\circ} \mathrm{C}$. As these detectors accumulate radiation dose from LHC operation it may become necessary to reduce these operating temperatures to minimize the effect of radiation damage. The evaporative cooling system is therefore intended to cool the Pixel and SCT trackers to $-15^{\circ} \mathrm{C}$; a requirement corresponding to 10 years' expected operation at LHC. The temperature uniformity in these detectors should be better than $2^{\circ} \mathrm{C}$, while the cooling system must remove a total of $62.4 \mathrm{~kW}$ of heat, mainly dissipated in the module front-end electronics. The cooling fluid must be radiation resistant and have good dielectric properties. Several fluorinated hydrocarbons have been investigated (Vacek et al. 2000). Experimental tests have identified octafluoropropane $\left(\mathrm{C}_{3} \mathrm{~F}_{8}\right)$ as the most suitable fluid for current operations. It has very good chemical stability under ionizing radiation and is non-flammable, non-toxic, non-corrosive and non-ozone depleting.

To achieve the required silicon substrate operating temperatures $\left(-15^{\circ} \mathrm{C}\right)$, an evaporation temperature of $-25^{\circ} \mathrm{C}$ is required in the on-detector cooling channels. The difference between this temperature and the silicon temperature is due to the thermal impedances of the mechanical structures coupling them. Many mechanical, electrical and thermal requirements must be satisfied by the cooling system. While meeting the required range of operating temperatures and temperature stability, the system must introduce the minimum of extra material into the silicon trackers to minimize the production of background particles and multiple scattering that would degrade the Inner Detector and calorimeter measurements. The cooling system should guarantee long term continuous operation with minimal maintenance periods. Evaporative cooling represents the best approach, combining a wider range of operating temperatures with much improved thermal uniformity and a mass flow 10-20 times less than in a monophase liquid cooling system for the same refrigerative power due to the exploitation of the latent heat of evaporation.

The present ATLAS ID evaporative cooling system (Battistin et al. 2005) is based on a compressioncondensation cycle using $\mathrm{C}_{3} \mathrm{~F}_{8}$ and operates in a similar way to a standard industrial direct expansion cooling plant. The thermodynamic cycle is shown in Figure 2.

$\mathrm{C}_{3} \mathrm{~F}_{8}$ vapour is cooled and condensed (B-C) and liquid $\mathrm{C}_{3} \mathrm{~F}_{8}$ is subcooled $\left(\mathbf{C}-\mathbf{D}_{\mathbf{1}}\right)$. Liquid $\mathrm{C}_{3} \mathrm{~F}_{8}$ is distributed 

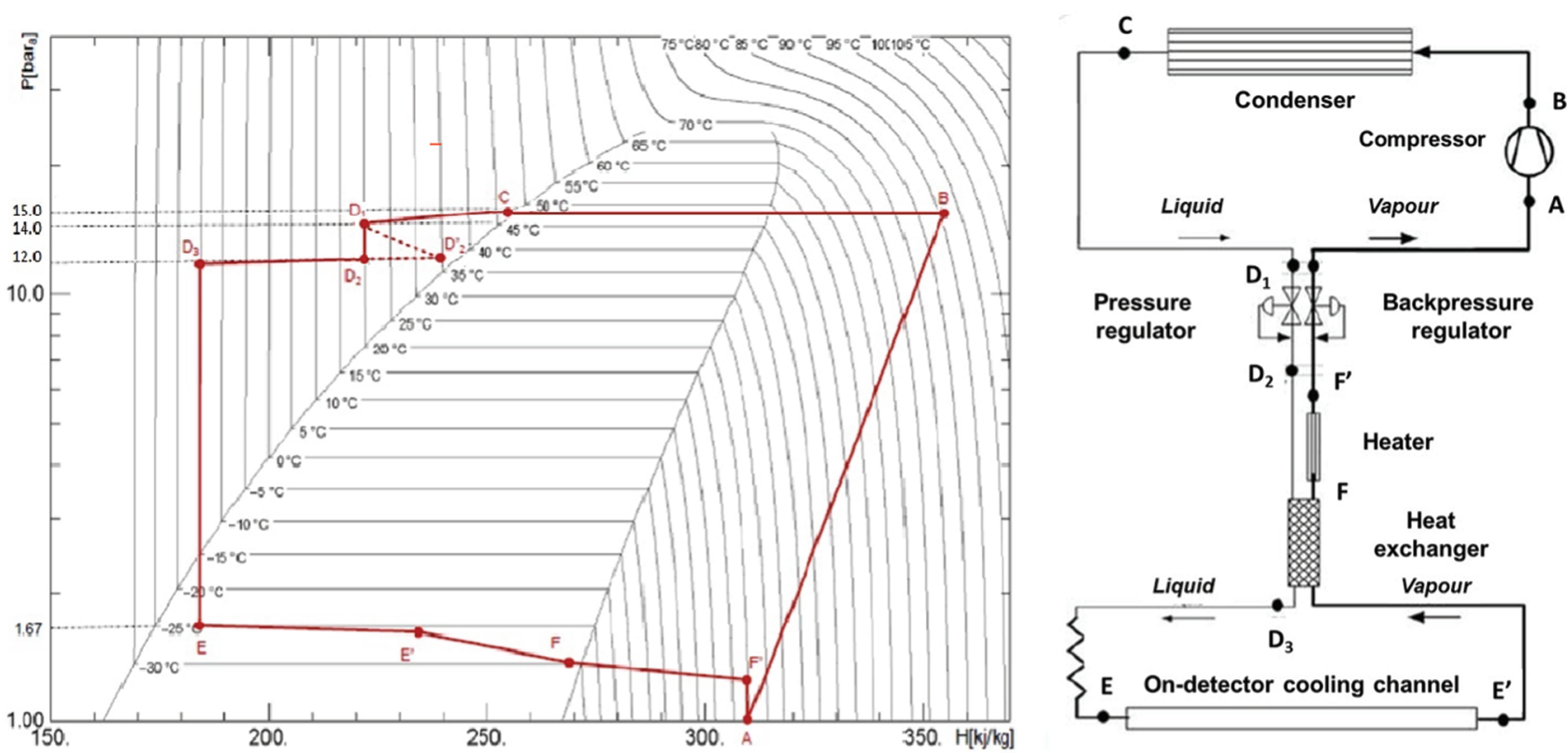

Figure 2: Thermodynamic cycle of the present compressor-driven $\mathrm{C}_{3} \mathrm{~F}_{8}$ evaporative cooling system and the corresponding components in the cooling circuits.

by manifolds located in distributions rack among 204 evaporative cooling circuits, 116 for the SCT and 88 for the Pixel detector. Following the distribution manifolds, $\mathrm{C}_{3} \mathrm{~F}_{8}$ liquid is delivered to the individual cooling circuits through uninsulated tubes over a length of $20 \mathrm{~m}$ in narrow cable trays alongside power cables. Although the cooling system was designed to accommodate a worst case rise in liquid temperature to $35^{\circ} \mathrm{C}$ in this zone (indicated by dashed line $\mathbf{D}_{\mathbf{1}}-\mathbf{D}_{\mathbf{2}}$, in Figure 2), this worst case was not realised in operation, the path $\mathbf{D}_{\mathbf{1}}-\mathbf{D}_{\mathbf{2}}$ being followed. Liquid coolant is further subcooled $\left(\mathbf{D}_{2}-\mathbf{D}_{3}\right)$ in the individual circuits through the use of recuperative heat exchangers located close to the detector, operating between the fluid exhaust (cold vapour with some unevaporated liquid present) and the (warm) input liquid. This exchange is crucial to increase the global efficiency of the system and maximizes the phase-change enthalpy available in the detectors. The subcooling allows a significant reduction of the mass flow (about 50\%), with a consequent impact on the size of the on-detector cooling tubes, the size and cost of the main plant and the overall system performance. The subcooled liquid (point $\mathbf{D}_{\mathbf{3}}$ ) is delivered through capillaries located immediately upstream of the on-detector cooling tubes. The coolant expands through the capillaries $\left(\mathbf{D}_{\mathbf{3}}-\mathbf{E}\right)$ and remains in saturation conditions. The temperature in the detector structure is set for each circuit by means of a back-pressure regulator (BPR) placed in the exhaust vapour return tube. The target evaporation temperature in the on-detector cooling pipes is $-25^{\circ} \mathrm{C}$, corresponding to a saturation pressure of 1.67 bar $_{\text {abs }}$ with $\mathrm{C}_{3} \mathrm{~F}_{8}$ coolant. The system works with a fixed flow in each circuit. The required mass flow depends on the power dissipated by each detector structure and was defined at the design stage by the geometry of the capillary (i.e. length and internal diameter). However, if needed, the flow can be slightly modified by setting the pressure of the inlet liquid with a pressure regulator (PR) located at the beginning of the inlet pipes. Both the BPR and the PR are located in distribution racks outside of the ATLAS detector for accessibility. The residual liquid due to the fixed flow constrain must be evaporated and the exit vapour temperature raised above the ATLAS cavern dew point $\left(12^{\circ} \mathrm{C}\right)$ in order to avoid condensation on the exterior surface of the return pipes. Electric heaters (F-F') are placed in the exhaust lines downstream and as close as possible to the heat exchanger (E'-F), and the detector structures. The heat exchangers and electric heaters are located inside common $\mathrm{CO}_{2}$-purged ID end-volumes. The heaters typically operate at a small fraction of their maximum power when the Pixel and SCT detectors are running near their full power. This allows the same refrigerative power to be supplied to each circuit regardless of the power load on the detector structures, even when the detectors are off. The heaters are controlled by a Programmable Logic Control (PLC) system using feedback from temperature sensors placed on their external surfaces and on the tubes immediately downstream. 
Coolant exits the heater in the superheated vapour state at ambient temperature (point F') and reaches the compressors via uninsulated return lines. The compressors raise the pressure of the coolant from around 1 bar $_{\text {abs }}$ to 15 bar $_{\text {abs, }}$, completing the thermodynamic cycle.

It can be seen from Figure 2 that the ATLAS ID evaporative cooling system is divided into two main parts separated by distribution/collection racks equipped with PRs and BPRs. The "internal" part includes all the components directly connected to each of the 204 individual detector cooling circuits: a recuperative heat exchanger, 1, 2 or 3 capillaries (depending on the cooling loop), the on-detector cooling channel(s), an electric heater on the return vapour line and the pipes linking the distribution racks to the on-detector components. The shared "external" part is presently composed of 7 compressors working in parallel and a condenser. The high radiation environment imposes the use of oil-free compressors in order to prevent the accidental circulation of entrained oil, which cannot be guaranteed to be sufficiently resistant to ionizing radiation. While $\mathrm{C}_{3} \mathrm{~F}_{8}$ will exit the detector only slightly activated, even small amount of compressor lubricating oil could be dangerous and might also damage the circulating $\mathrm{C}_{3} \mathrm{~F}_{8}$. The compressors (Haug model QTOGX-160/80) were especially modified to satisfy the very demanding compression ratio of the system. The maximum admissible output pressure of these compressors is 17 bar $_{\text {abs }}$ and their minimum suction pressure is 0.8 bar $_{\text {abs. }}$. These pressures encompass the system requirements (maximum output pressure: 15 bar $_{\text {abs }}$ and minimum aspiration pressure: 1 bar $_{\text {abs }}$ ). Although the compressors have been improved and are presently working satisfactorily they still represent the weakest component of the system, and need frequent maintenance.

\subsection{Replacement of the present compressor-driven recirculator with a thermosiphon}

The external part of the cooling system will be modified with the replacement of the compressors by a gravitydriven "thermosiphon" natural circulation plant. While the compressor reliability issue represents the main motivation for the thermosiphon replacement, another important consideration was the observation that the attainable evaporation temperature with $\mathrm{C}_{3} \mathrm{~F}_{8}$ was higher than desired, due to greater than expected pressure drops across the vapour side of the recuperative heat exchangers in some of the 204 parallel cooling circuits. While this does not represent a problem in the early phase of operation of the
ATLAS Inner Detector, lower temperature will be necessary later as the silicon substrates of the SCT and Pixel detectors accumulate more radiation damage. As previously mentioned, the critical requirement of the cooling system is to reach and maintain a stable operating temperature of $\leq-$ $25^{\circ} \mathrm{C}$ in the detector cooling structures operating at the maximum power load. This temperature is specified at the inlet end of the on-detector cooling channels (following the capillaries), and corresponds to an absolute pressure of 1.67 bar $_{a b s}$ in pure $\mathrm{C}_{3} \mathrm{~F}_{8}$. While pressure drops in elements of the exhaust returns to the compressor inputs conspire to increase the operating temperature of the silicon detectors a baseline is set by the typical minimum operable compressor aspiration pressure of $1 \mathrm{bar}_{\mathrm{abs}}$. It was realized that the use of a thermosiphon could reduce this baseline pressure to around 500 mbar $_{\text {abs }}$ (see Section 2), making it easier to achieve the required on-detector evaporation pressure of 1.67 bar $_{\text {abs }}$ with $\mathrm{C}_{3} \mathrm{~F}_{8}$.

In another parallel approach we are also investigating the use of fluorocarbon blends to reduce the evaporation temperature for the same operating pressure. Hexafluoroethane $\left(\mathrm{C}_{2} \mathrm{~F}_{6}\right)$ is characterized by a much lower saturation temperature than $\mathrm{C}_{3} \mathrm{~F}_{8}$ at the same pressure. A blend containing $20-25 \% \quad \mathrm{C}_{2} \mathrm{~F}_{6}$ in $\mathrm{C}_{3} \mathrm{~F}_{8}$ would enable a lower evaporation temperature for the same pressure, thus satisfying the system requirements. A series of tests has been performed over a range of $\mathrm{C}_{2} \mathrm{~F}_{6} / \mathrm{C}_{3} \mathrm{~F}_{8}$ molar concentrations, using a test station that thermally reproduced an installed SCT cooling circuit (Bates et al. 2013; 2015; Rossi et al., 2014). Future studies of blend circulation in a thermosiphon are envisioned.

The proposed thermosiphon also presents additional interesting advantages;

- coolant loss reduction, through a reduced number of seals - as a direct consequence of the simplification of the main loop;

- improved cleanliness, avoiding pollution caused by wear to reciprocating components (particles from piston rings, etc.);

The differences between the present compressor-driven evaporative cooling system and the new thermosiphon system are illustrated in Figures 3 and 4.

\section{The full scale thermosiphon}

The ATLAS thermosiphon evaporative cooling circulator exploits the peculiarities of LHC experiments located around $100 \mathrm{~m}$ underground. The great height difference 


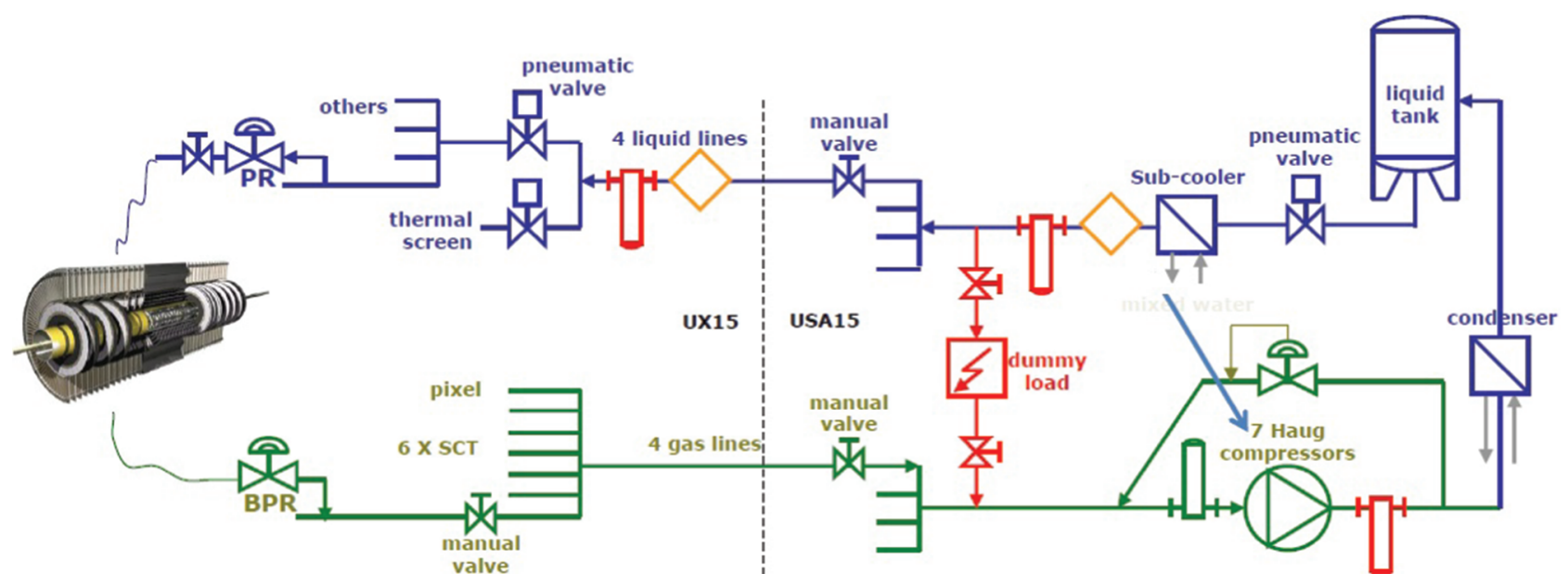

Figure 3: Simplified schematic (internal \& external parts) of the present compressor-driven evaporative cooling system of the ATLAS inner detector.

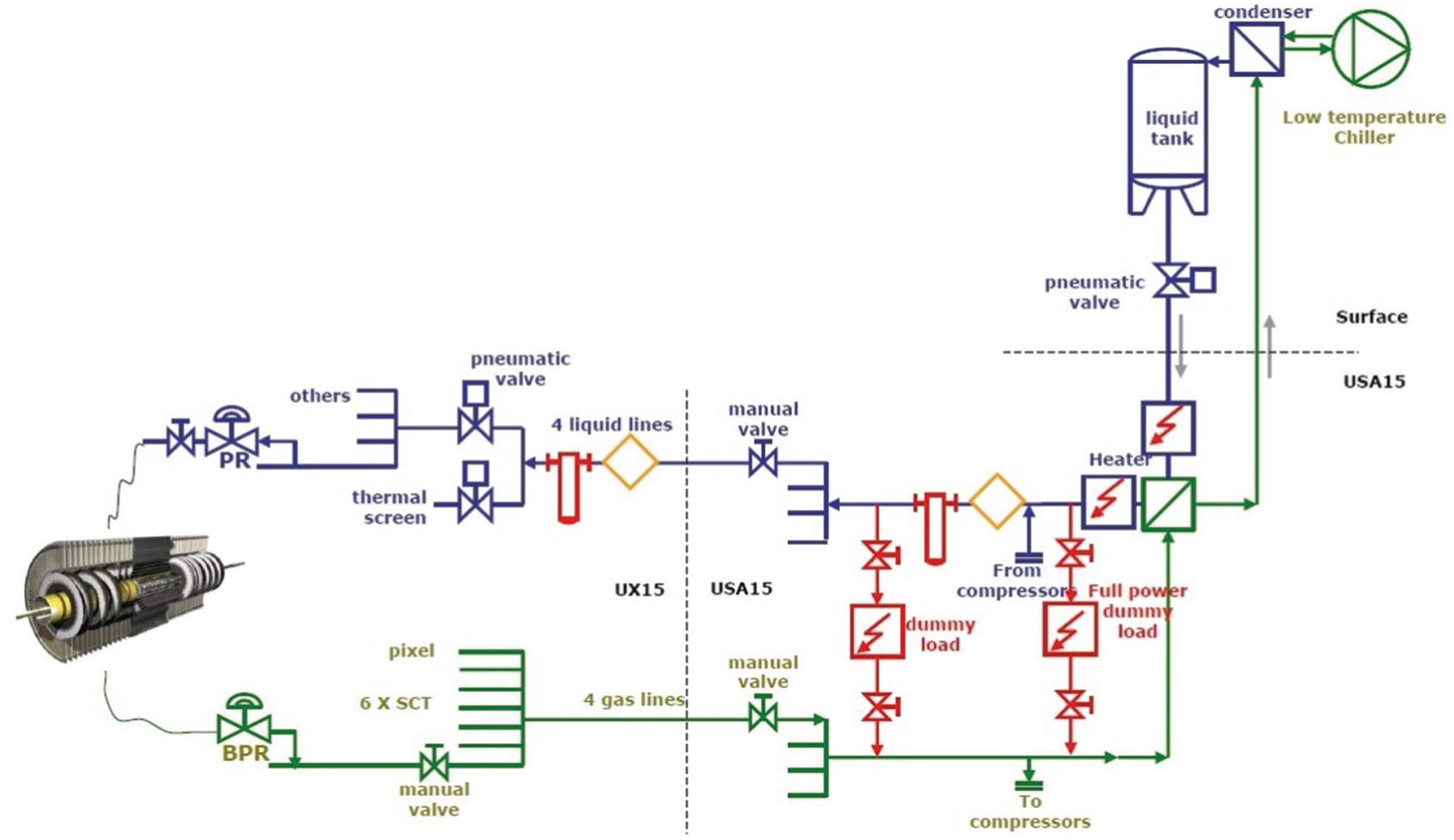

Figure 4: Simplified schematic of the new system based on the full-scale thermosiphon.

(92 $\mathrm{m}$ ) between the underground cavern housing the ATLAS experiment and the surface is used to allow natural circulation of the coolant with no active components (pumps or compressors) in the primary coolant loop. This is achieved by condensing the fluid at a lower temperature/pressure than the evaporation temperature/pressure, but at a higher altitude. This system must provide around
$60 \mathrm{~kW}$ of on-detector cooling capacity, supplying high pressure liquid to the same (inaccessible) on-detector components of the cooling system, while guaranteeing the required evaporation pressure along the on-detector cooling channels.

The full scale thermosiphon (Figure 5) is composed of four separate circuits: 
1. a water circuit: cooling the first stage of the chiller circuit. The water is taken from cooling towers at approximately $25^{\circ} \mathrm{C}$;

2. a chiller circuit: using a two-stage vapour compression cycle to cool down perfluorohexane $\left(\mathrm{C}_{6} \mathrm{~F}_{14}\right)$ "brine" heat transfer liquid to $-70^{\circ} \mathrm{C}$. The chiller operates in cascade: the first stage using R404a and the second stage using R23.

3. a brine circuit: consisting of a $\mathrm{C}_{6} \mathrm{~F}_{14}$ closed loop, which is used to condense the $\mathrm{C}_{3} \mathrm{~F}_{8}$ through heat exchange across the tubes in the condenser. A liquid mass flow of around $40 \mathrm{~kg} / \mathrm{s}$ of $\mathrm{C}_{6} \mathrm{~F}_{14}$ is used to condense $1.2 \mathrm{~kg} / \mathrm{s}$ of $\mathrm{C}_{3} \mathrm{~F}_{8}$ for the evacuation of about $60 \mathrm{~kW}$ of heat from the ATLAS Inner Detector. The $\mathrm{C}_{3} \mathrm{~F}_{8}$ brine temperature and flow rate have a strong effect on to $\mathrm{C}_{3} \mathrm{~F}_{8}$ condensation temperature and pressure, and a sophisticated control system based on industrial programmable logic controllers is implemented. The $\mathrm{C}_{6} \mathrm{~F}_{14}$ is used as the transfer fluid mainly for its chemical similarity to $\mathrm{C}_{3} \mathrm{~F}_{8}$ and corresponding radiation resistance. The detector would not be damaged in the event of leaks across the condenser into the thermosiphon primary circuit. The fluid compatibility would also allow primary coolant to be restored by distillation if necessary.

4. the thermosiphon primary circuit: condensing $\mathrm{C}_{3} \mathrm{~F}_{8}$ at the surface to produce a liquid column from the surface to the cavern with an exit pressure given by the hydrostatic column of 92 metres of fluid. The liquid evaporates in the unchanged on-detector cooling channels and returns to the surface as vapour by differential pressure.

\subsection{The thermosiphon primary circuit}

The thermosiphon must provide at least the same performance as the present compressor system; delivering coolant to the detector liquid supply manifold at $20^{\circ} \mathrm{C}$ and 15 bar $_{\text {abs }}$ and recovering vapour from the return manifold at $20^{\circ} \mathrm{C}$, and - crucially - at a pressure $<1$ bar $_{\text {abs. }}$ The $92 \mathrm{~m}$ height difference hydrostatically generates the 15 bar liquid pressure. The full power cooling specification of

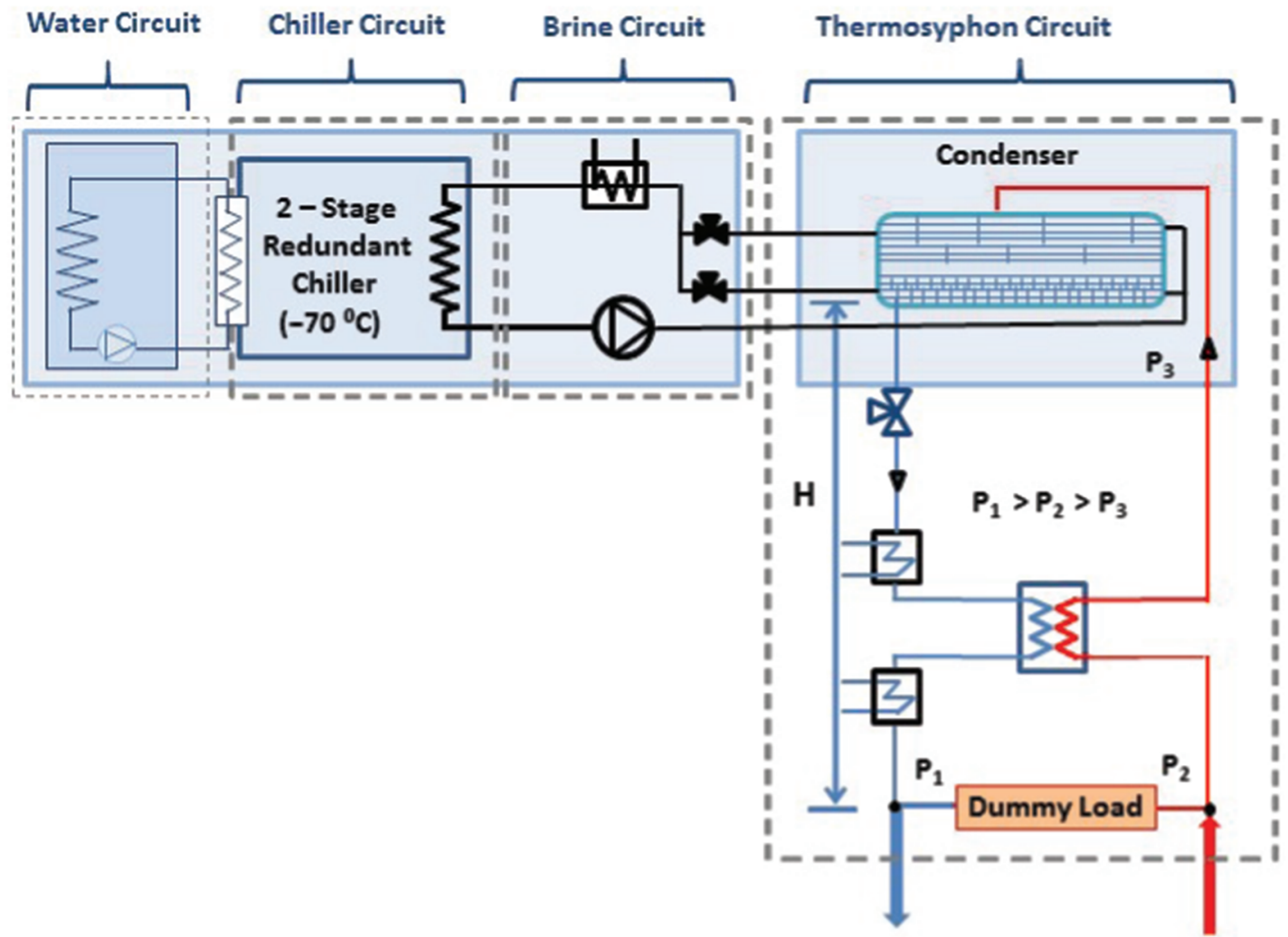

\section{Liquid Supply Vapour return To detector from detector}

Figure 5: Schematic showing the water circuit, chiller and brine circuits of the full scale thermosiphon. 


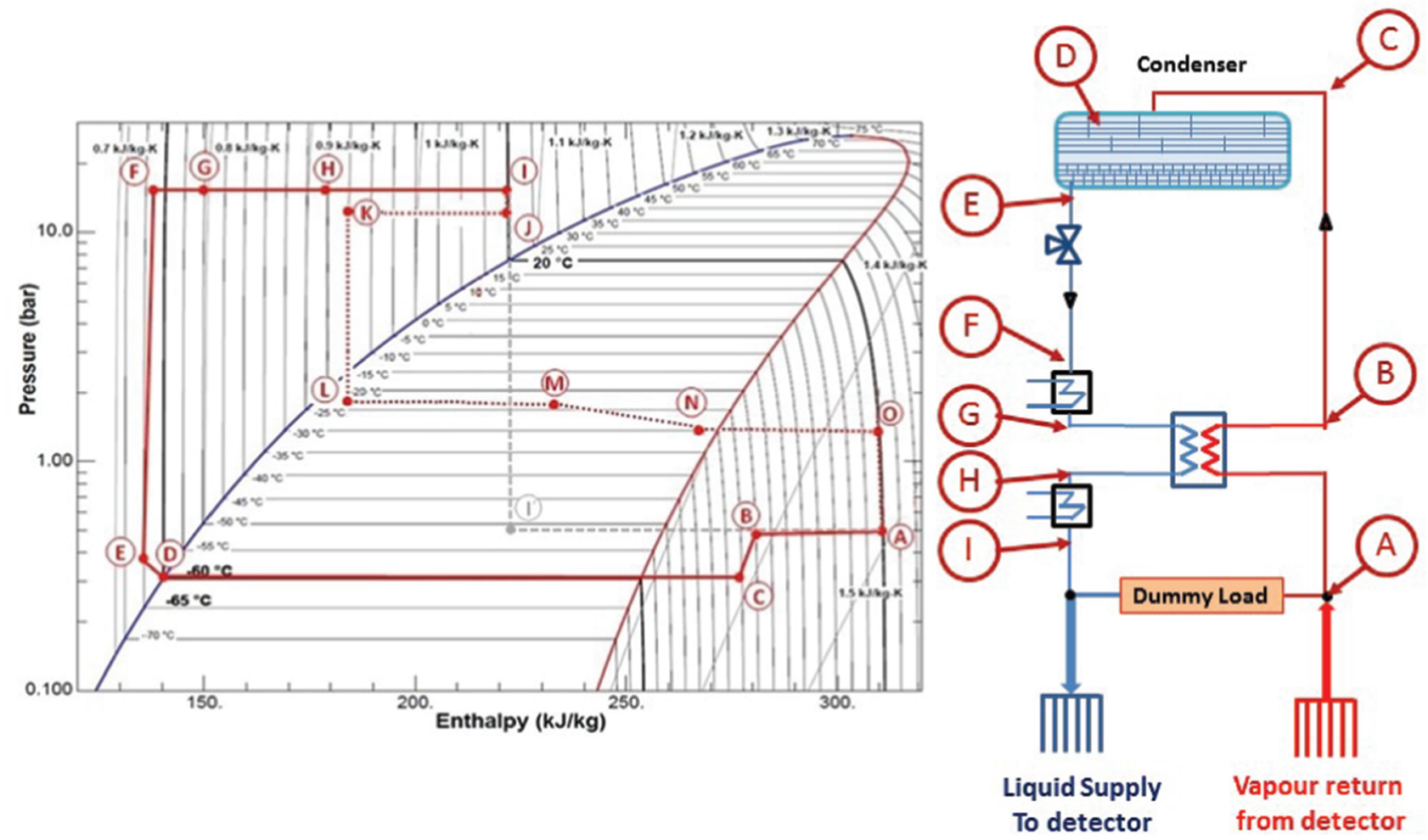

Figure 6: Thermodynamic cycle of the full scale thermosiphon system.

$\sim 62.4 \mathrm{~kW}$ at $-25^{\circ} \mathrm{C}$ requires a mass flow of $1.2 \mathrm{~kg} / \mathrm{s}$ in the primary coolant loop (Botelho Direito et al. 2010).

The thermodynamic cycle of the thermosiphon circuit and the corresponding schematic are shown in Figure 6. On the thermodynamic cycle, the part corresponding to the external thermosiphon circuit is marked with a solid line $(\mathbf{A} \rightarrow \mathbf{I})$ while the rest of the circuit (inside the detector envelope) is marked with a dashed line. The red line of the schematic represents the vapour return, while the blue line represents the liquid supply to the detector. The fluid exits the detector as superheated vapour at ambient temperature (point $\mathbf{O}$ to be compared with point $\mathbf{F}$ ' in Figure 2). It then passes through $30 \mathrm{~m}$ of tubing and a backpressure regulator (one of which sets the evaporation pressure in each of the 204 parallel cooling circuits) to a recuperation manifold from where it re-enters the external thermosiphon primary coolant circuit (point A) at 0.5 bar $_{\text {abs }}$, $20^{\circ} \mathrm{C}$. Coolant in vapour phase then passes through a heat exchanger to be cooled to $-20^{\circ} \mathrm{C}$ at approximately the same pressure (point $\mathbf{B}$ ). The heat exchanger is used to reduce the overall energy consumption of the cooling system to around $170 \mathrm{~kW}$. Cooling the return vapour (A-B) in counterflow with cold liquid reduces the condensation power requirement at the condenser, while the heating of the liquid $(\mathbf{G}-\mathbf{H})$ reduces the heating power needed to raise its temperature to avoid condensation in the un-insulated liquid tubes running from the distribution manifolds to the detector.

The line from point $\mathbf{B}$ to $\mathbf{C}$ represents the pressure drop along the vapour return line, from the bottom of the plant to the surface condenser. The estimated pressure drop of 0.2 bars includes the vapour column weight and the frictional pressure drop. At point $\mathbf{C}$ the vapour enters the condenser. This unit contains two functional parts sharing the same envelope: the condenser itself and a chilled (sub-cooled) liquid storage volume. The condenser is large enough to recover and store all the fluid when the system is stopped. The $\mathrm{C}_{3} \mathrm{~F}_{8}$ vapour is condensed at a temperature of $-60^{\circ} \mathrm{C}$, corresponding to a saturation pressure of 309 mbar $_{\text {abs }}$ (point $\mathbf{D}$ ) and falls as droplets into the chilled liquid volume. Since the temperature of the liquid droplets is very close to the saturation temperature it is necessary to further cool the bulk liquid to prevent boiling which even a small amount of heat entering from the outside would cause. A second heat exchanger, placed in the tank, sub-cools down the liquid to $-65^{\circ} \mathrm{C}$ (point $\mathbf{E}$ ). The pressure at point $\mathbf{E}$ is also slightly higher due to the liquid level of $\mathrm{C}_{3} \mathrm{~F}_{8}$ in the condenser. The line $\mathbf{E}-\mathbf{F}$ shows the increase of hydrostatic pressure along the descendant $92 \mathrm{~m}$ liquid supply tube. The liquid reaches the bottom of 
the plant at 16.1bar ${ }_{a b s}$ and a few degrees warmer, depending on the free convection of the air in the shaft. Given the low temperatures of the supply and return lines of the thermosiphon, it is essential to insulate the pipes. The temperature increase due to the isentropic compression is insignificant (less than $0.5^{\circ} \mathrm{C}$ ). At point $\mathbf{F}$, the liquid is heated a few degrees to enter a heat exchanger at the optimum temperature (point $\mathbf{G}$ ). This temperature is $-51^{\circ} \mathrm{C}$ and chosen to be slightly higher than the corresponding saturation temperature $\left(-51.3^{\circ} \mathrm{C}\right)$ of the counterflowing ascendant vapour at the local pressure of 0.5 bar $_{\text {abs }}$ (points A, B), to prevent entrained $\mathrm{C}_{3} \mathrm{~F}_{8}$ liquid droplets (from the dummy load) entering the ascendant vapour return line. The heat exchanger raises the liquid $\mathrm{C}_{3} \mathrm{~F}_{8}$ temperature from $-51^{\circ} \mathrm{C}$ to $-20^{\circ} \mathrm{C}$, at point $\mathbf{H}$. Following the heat exchanger an electric heater raises the liquid temperature to $20^{\circ} \mathrm{C}(\mathbf{H} \rightarrow \mathbf{I})$. Beyond this point $\mathrm{C}_{3} \mathrm{~F}_{8}$ liquid enters the unmodified internal cooling circuits.

The thermosiphon recirculator is equipped with a bypass (opening path $\mathbf{I} \rightarrow \mathbf{A}$ ) incorporating a dummy load situated near the bottom of the plant. The by-pass allows the cooling plant to be commissioned while the SCT and Pixel trackers are still in operation with the present compressor system. Also it will enhance the stability of the external cooling plant by keeping a minimum thermal load on the thermosiphon in the event that large parts of the SCT and Pixel trackers are turned off. The dummy load is equipped with flow regulation, an expansion device ( $\left.\mathbf{I} \rightarrow \mathbf{I}^{\prime}\right)$ and electric heater serving as an evaporator and superheater. From point I' to point $\mathbf{A}$ the fluid will be evaporated and superheated to $20^{\circ} \mathrm{C}$. The characteristics of each point of the thermodynamic cycle, from $\mathbf{A}$ to $\mathbf{I}$, are detailed in Table 1 for the normal operation cycle and the by-pass cycle explained above.

\section{The mini thermosiphon and the $2 \mathrm{~kW}$ thermosiphon}

In order to verify the feasibility of the full scale thermosiphon, two prototypes were built: the "minithermosiphon" and the " $2 \mathrm{~kW}$ thermosiphon". The main differences between these systems and the full scale $(60 \mathrm{~kW})$ thermosiphon are the total available height for the mini-thermosiphon and the cooling power for the 2 $\mathrm{kW}$ thermosiphon. Apart from these differences the cooling principle of the systems is the same.

The scope of the test facilities was to remove the heat generated by thermal loads simulating part of the detector and dissipate this heat by condensing the $\mathrm{C}_{3} \mathrm{~F}_{8}$ vapour at a higher altitude. The basic schematics of the mini and $2 \mathrm{~kW}$ thermosiphons are shown in Figure 7. They are represents steps in the development of the full scale thermosiphon shown in Figure 5. The mini-thermosiphon was a particularly simple circuit where the detector was simulated with a dummy electric resistive load. The $2 \mathrm{~kW}$ thermosiphon was more sophisticated and could run in two different operational modes: by-pass cycle and "test section" or "detector" cycle.

\subsection{The mini-thermosiphon}

The mini-thermosiphon (Botelho Direito and Rodriguez, 2011) was a small scale system, both in terms of height and cooling power, built to validate the operation of a two-phase thermosiphon with $\mathrm{C}_{3} \mathrm{~F}_{8}$ coolant and to gain experience with the operation of a vertical plant. The condenser was located $17.4 \mathrm{~m}$ above a heat load

Table 1: Nominal operating points of the ATLAS full scale thermosiphon operation with $\mathrm{C}_{3} \mathrm{~F}_{8}$.

\begin{tabular}{|c|c|c|c|c|c|}
\hline Operating point & $\frac{\text { Pressure }}{\left[\mathrm{bar}_{\mathrm{abs}}\right]}$ & $\frac{\text { Temperature }}{\left[{ }^{\circ} \mathrm{C}\right]}$ & $\frac{\text { Density }}{\left[\mathrm{kg} / \mathrm{m}^{3}\right]}$ & $\frac{\text { Enthalpy }}{[\mathrm{kJ} / \mathrm{kg}]}$ & Physical State \\
\hline A & 0.5 & 20 & 3.90 & 310.8 & Superheated vapour \\
\hline B & 0.495 & -20 & 4.65 & 280.6 & Superheated vapour \\
\hline C & 0.309 & $-25^{\mathrm{a}}$ & 2.85 & 277.4 & Superheated vapour \\
\hline D & 0.309 & -60 & 1,699 & 140.3 & Saturated liquid \\
\hline$E$ & $0.4^{\mathrm{b}}$ & -65 & 1,717 & 135.7 & Sub-cooled liquid \\
\hline$F$ & 16.1 & -62 & 1,712 & 139.0 & Sub-cooled liquid \\
\hline G & 16.1 & -51 & 1,672 & 149.2 & Sub-cooled liquid \\
\hline $\mathrm{H}$ & 16 & -20 & 1,552 & 179.4 & Sub-cooled liquid \\
\hline I & 16 & 20 & 1,365 & 222.0 & Sub-cooled liquid \\
\hline l' & 0.5 & -51 & 7.89 & 222.0 & Two-phase $x=0.6$ \\
\hline
\end{tabular}

Notes: ${ }^{\text {aTemperature of }}-28^{\circ} \mathrm{C}$ from thermal expansion plus $+3^{\circ} \mathrm{C}$ due to heat pick-up.

${ }^{\mathrm{b}}$ Estimated value - depending on the liquid level inside the condenser taken here to be 1 metre. 

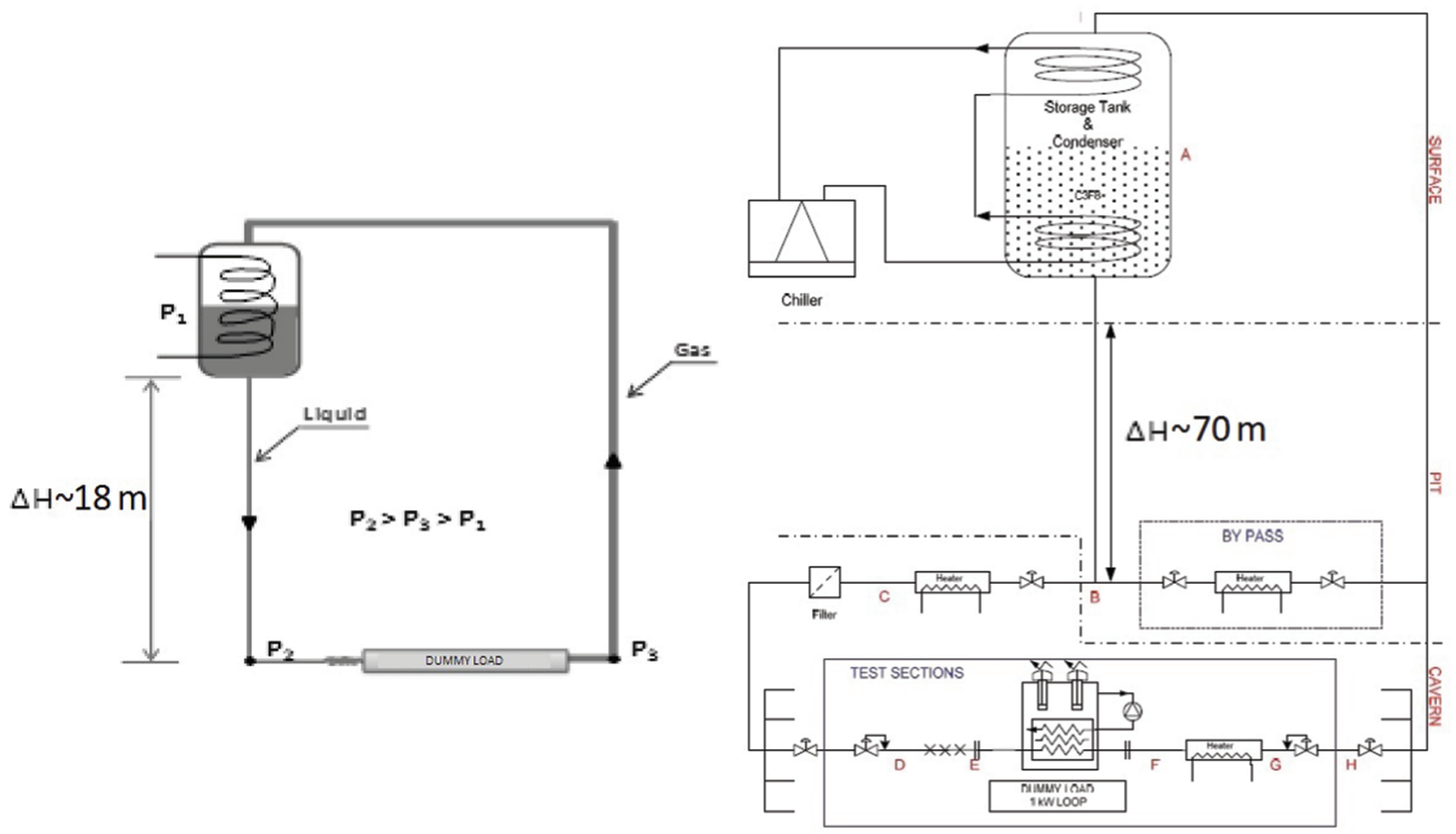

Figure 7: Basic schematics of the mini-thermosiphon (left) and the $2 \mathrm{~kW}$ thermosiphon (right).

simulating part of the tracker. A recirculating liquid chiller circulated $\mathrm{C}_{6} \mathrm{~F}_{14}$ "brine" through a coiled heat exchanger within the condenser to remove the heat recovered from the thermal load. The total condensation power ranged from 3 to $5 \mathrm{~kW}$ depending on the condenser temperature. Tests were made over an evaporation temperature range from $15 \rightarrow-22^{\circ} \mathrm{C}$, and focussed in detail on the start-up and shut down phases of the vertical plant. The thermodynamic cycle ${ }^{1}$ of the mini-thermosiphon, progressing from start-up to the cold running cycle is shown in Figure 8.

To properly run the plant, it was found that liquid in the condenser and the supply line had to remain subcooled while the outlet vapour had to be superheated along the return vapour line to avoid local condensation. In order to maintain these conditions, the plant had to be run with a minimum mass flow, avoiding liquid line boiling (when running at lower than ambient temperatures) and return vapour condensation (when running at higher than ambient temperatures). This led to the addition of a parallel dummy load at the low level of the vertical plant of the $2 \mathrm{~kW}$ and full size thermosiphons.

1 Calculated with NIST-REFPROP verson 23 (Lemmon et al. 2010).

\subsection{The $2 \mathrm{~kW}$ thermosiphon}

A second thermosiphon system (with $2 \mathrm{~kW}$ condensation power) was built to explore the behaviour of the plant in a prototype characterized by a similar height to that of the final full scale system (Botelho Direito 2012). The liquid column of this thermosiphon was $70 \mathrm{~m}$ and the nominal evaporation temperature of the fluid was $40^{\circ} \mathrm{C}$. The plant could be operated in a "detector" cycle and a by-pass cycle, aimed to facilitate the start-up of the system. In the by-pass cycle the coolant is evaporated by electrical heaters placed in the by-pass itself. The "detector" cycle simulated the behaviour of part of the ATLAS ID silicon tracker with a dummy load composed of two parallel heaters loops, each dissipating $1 \mathrm{~kW}$.

The main difference between the "detector" cycle of the $2 \mathrm{~kW}$ thermsiphon and the full scale thermosiphon is the cooling capacity of the plant. A comparison of their main parameters is shown in Table 2. Other important differences were the absence of a separate liquid subcooling coil in the $2 \mathrm{~kW}$ condenser and the absence of a heat exchanger between the descendant liquid and ascendant vapour. The studies with the $2 \mathrm{~kW}$ thermosiphon highlighted the necessity of the liquid line subcooling that appeared in the final plant. Although a 


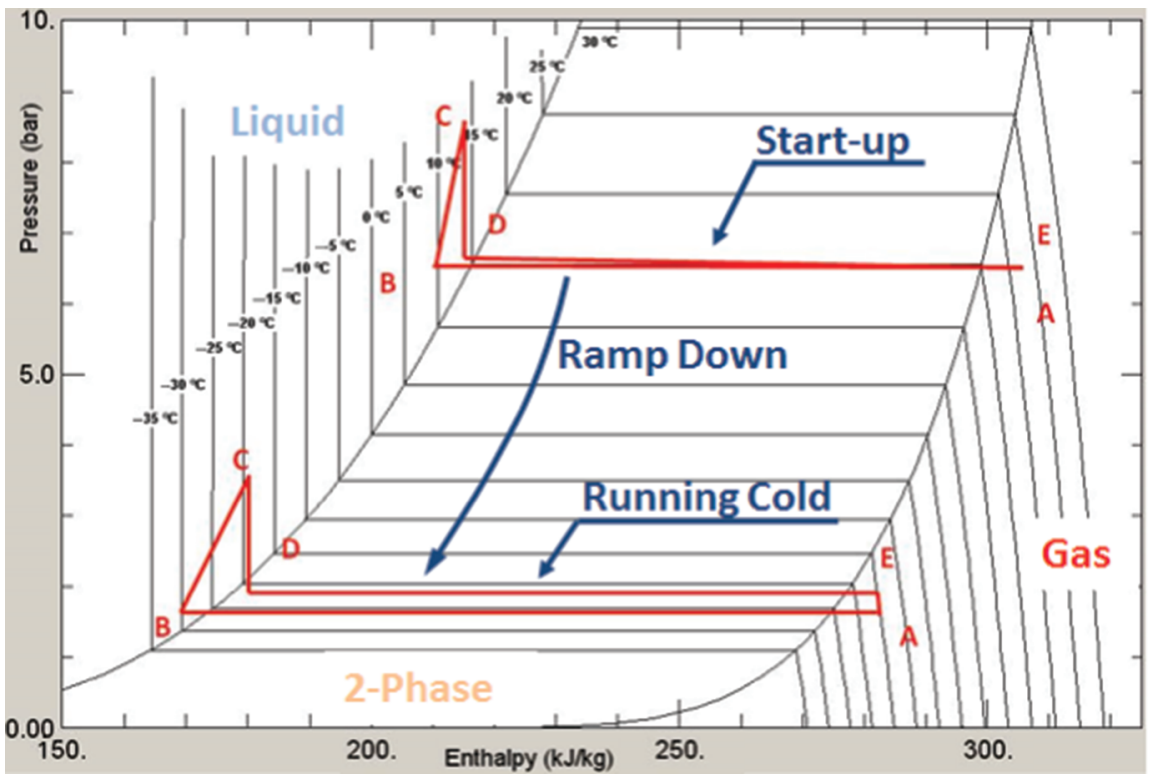

Figure 8: Mini-thermosiphon thermodynamic cycle with $\mathrm{C}_{3} \mathrm{~F}_{8}$ from start-up to cold run.

Table 2: Summary of the main design parameters of the $2 \mathrm{~kW}$ and full scale thermosiphon.

\begin{tabular}{lrr}
\hline Main design parameters & $\mathbf{2 ~ k W}$ thermosiphon & Full scale thermosiphon \\
\hline Total cooling capacity of the system & $2 \mathrm{~kW}$ & $62.4 \mathrm{~kW}$ \\
Nominal evaporation temperature & $-40^{\circ} \mathrm{C}$ & $-51^{\circ} \mathrm{C}^{\mathrm{a}}$ \\
Nominal condensation temperature & $-48.8^{\circ} \mathrm{C}$ & $-60^{\circ} \mathrm{C}$ \\
Pressure at the condenser/tank & $0.57 \mathrm{bar}_{\text {abs }}$ & $0.309 \mathrm{bar}_{\text {abs }}$ \\
Nominal liquid pressure at the supply manifold & $13.5 \mathrm{bar}_{\text {abs }}$ & $16 \mathrm{bar}_{\text {abs }}$ \\
Nominal vapour pressure at the return manifold & $0.8 \mathrm{bar}_{\mathrm{abs}}$ & $0.5 \mathrm{bar}_{\mathrm{abs}}$ \\
Liquid temperature at the supply manifold & $+20^{\circ} \mathrm{C}$ & $+20^{\circ} \mathrm{C}$ \\
Vapour temperature at the return manifold & $+20^{\circ} \mathrm{C}$ & $+20^{\circ} \mathrm{C}$ \\
\hline
\end{tabular}

Note: ${ }^{\text {a }}$ In dummy load operation.

sudden closure of a valve at the bottom of the plant presented no risk of "water hammer", the $2 \mathrm{~kW}$ thermosiphon tests showed the presence of pressure pulses at the bottom of the plant ( $70 \mathrm{~m}$ below the condenser) caused by the sudden start-up of liquid flow into the previously empty vertical liquid line. It was felt that this could present a potential risk to operation of the Pixel and SCT detectors with the full scale thermosiphon, since these detectors are linked through the ATLAS magnet system to liquid distribution manifolds via copper tubes with a maximum pressure rating of 25 bar. A soft-start drive was therefore added to the liquid exit valve of the condenser of the full size thermosiphon.

The tests allowed the optimization of the final cooling plant. Many relevant running control parameters were identified and the time constants of the full scale thermosiphon were estimated by scaling from the $2 \mathrm{~kW}$ thermosiphon. The tests also confirmed that the start-up and ramp down procedures developed in the $2 \mathrm{~kW}$ thermosiphon could be adapted to a thermosiphon approximating the final height.

\section{Conclusion}

The ATLAS experiment is one of the two largest experiments at the CERN Large Hadron Collider. The silicon tracker of the ATLAS Inner Detector must be kept at low temperature to minimise damage to the semiconducting characteristics of the silicon in the high radiation environment. Currently the detectors are cooled by means of a compressor-driven evaporative fluorocarbon recirculator operating with $\mathrm{C}_{3} \mathrm{~F}_{8}$.

Mainly motivated by questions of long-term reliability, the compressors will be replaced by a $60 \mathrm{~kW}$ capacity gravity-driven thermosiphon recirculator with no active components in the primary loop. The thermosiphon takes advantage of the special features of the LHC experiments 
located around $100 \mathrm{~m}$ underground. The $\mathrm{C}_{3} \mathrm{~F}_{8}$ coolant will be condensed at a lower temperature/pressure than the evaporation temperature/pressure, and at a higher altitude. This system will be compatible with existing inaccessible internal ("on-detector") cooling circuit elements and will provide high pressure $\mathrm{C}_{3} \mathrm{~F}_{8}$ liquid at room temperature at the inlet of the detectors while guaranteeing the required evaporation temperature of $-25^{\circ} \mathrm{C}$ along the on-detector cooling channels. Two small scale thermosiphon plants were built to verify the feasibility of such a system with $\mathrm{C}_{3} \mathrm{~F}_{8}$ coolant. The tests demonstrated operation over the required detector operating temperature range and provided valuable experience on thermosiphon plant operation including the ramp down from warm start-up to long-term cold operation. In particular a $2 \mathrm{~kW}$ thermosiphon demonstrated unattended longterm stable running over a period of several weeks. The full scale thermosiphon is now in the commissioning phase and the full operation of the system is planned for late 2015.

Acknowledgements: We acknowledge the ATLAS inner detector group and the particle physics group of the University of Glasgow. Finally we acknowledge the support from the U.K. Science and Technology Facilities Council.

Funding: The authors wish to thank CERN and their home institutes for support for this project. We acknowledge the support through grants LG13009 and MSM6840770035 of the Ministry of Education, Youth and Sports of the Czech Technical University, Prague. University of Indiana participation was supported through U.S. Department of Energy contract DE-AC02-98CH10886. University of Oklahoma participation was supported through DOE contract DEFG02-04ER41305.

\section{References}

Aad, G. et al., 2008. The ATLAS experiment at the CERN Large Hadron Collider. Journal of Instrumentation 3, 08, S08003.

Aitree, G. et al., 2008. The evaporative cooling system for the ATLAS Inner Detector. JINST 3, 07, P07003.

ATLAS Collaboration, 1997. Inner Detector technical design report, vols 1\&2, CERN-LHCC-97-016 \& 17.

ATLAS Collaboration, 1998. Pixel Detector technical design report, CERN-LHCC-98-13.

Bates, R. et al., 2013 A combined ultrasonic flow meter and binary vapour mixture analyzer for the ATLAS silicon tracker. Journal of Instrumentation 8, 02, P02006.

Bates, R. et al., 2015. The cooling capabilities of C2F6/C3F8 saturated fluorocarbon blends for the ATLAS silicon tracker. Journal of Instrumentation 10 03, P03027.

Battistin, M. et al., 2005. ATLAS Evaporative Cooling System External Part to the Detector, CERN. https://edms.cern.ch/ document/557650/1

Botelho Direito, J. et al., 2010. General Description of the Full Scale Thermosiphon Cooling System for ATLAS SCT and Pixel EDMS 1083852, CERN. https://edms.cern.ch/file/1083852/1/ Technical_Note_60kW_Thermosiphon.pdf.

Botelho Direito, J., 2012. 2kW thermosiphon Tests Results, CERN. https://edms.cern.ch/file/1245465/1/1245465_PX15_ Thermosyphon_tests_results.pdf.

Botelho Direito, J., Rodriguez, E. P., 2011. Mini-thermosiphon Tests Results, CERN. https://edms.cern.ch/file/1083837/2/ Mini-Thermosyphon_test_results.pdf.

Lemmon, E., Huber, M., McLinden, M., 2010. REFPROP Standard reference database 23, version 9.0 U.S. National Institute of Standards and Technology.

Rossi, C. et al., 2014. A new ultrasonic instrument for combined real-time flowmetry and binary vapour determination in a fluorocarbon evaporative cooling system, 13th Int. Conf. Multiphase Flow In Industrial Plant (Genoa).

Vacek, V. et al., 2000. Perfluorocarbons and their use in cooling systems for semiconductor particle detectors. Fluid Phase Equilibria 174, 191-201. 